\title{
Clusius em Portugal: UMA VIAGEM, MÚLTIPLOS ENCONTROS
}

\author{
Teresa Nobre de Carvalho \\ Centro Interuniversitário da História da Ciência e da Tecnologia \\ Universidade de Lisboa
}

Resumo: Em 1564-1565, Clusius (1526-1609) efectuou uma viagem à Península Ibérica enquanto tutor do jovem herdeiro do empório dos Függer. A viagem, que durou cerca de um ano, levou os dois homens às mais destacadas cidades peninsulares. Se as deambulações pelos campos lusitanos revelaram ao botânico as peculiaridades da flora portuguesa, a inevitável passagem por Lisboa assegurou-lhe encontros surpreendentes. O embate com uma obra recém-chegada do Oriente - Colóquios dos Simples e Drogas he Cousas Mediçinais da Índia, de Garcia de Orta, (Goa, ${ }_{1563}$ - - despertou a sua atenção. O texto que agora se apresenta tece algumas considerações sobre os múltiplos impactos que a passagem do botânico por Portugal causou na ciência europeia de então.

Palavras chave: Clusius, Jacob Függer, Garcia de Orta, Colóquios dos Simples, flora de Portugal.

\section{Clusius In Portugal: One voyage, Multiple Encounters}

Aвstract: From 1564 to 1565 , Clusius (1526-1609) travelled to the Iberican Peninsula as the tutor of the young heir of the Függers. This journey, which lasted nearly a year, took the two men to the most important cities in the Peninsula. If strolling through the Portuguese countryside demonstrated the peculiarities of the local flora to the botanist, the decreed visit to Lisbon offered many surprising experiences. The encounter with the work recently arrived from the Orient —Colóquios dos Simples e Drogas he Cousas Mediçinais da Índia, by Garcia de Orta (Goa, I563) - awakened his interest. The present article weaves together considerations on the multiple impacts that the botanist's voyage to Portugal caused in European science of the time.

KeYwords: Clusius, Jacob Függer, Garcia de Orta, Colóquios dos Simples, flora de Portugal. 


\section{ITINERÁRIO IBÉRICO}

Entre finais de 1564 e princípios de 1565 , Clusius (I526-i609) acompanhou o jovem Jacob Függer (1542-1598) numa viagem através da Ibéria. ${ }^{1}$ Esta peregrinação por terras das Hispânias teve como principal objectivo complementar a formação humanista do jovem herdeiro do empório comercial alemão. Esta importante dinastia de banqueiros germânicos estava particularmente implicada no financiamento das grandes viagens de exploração de portugueses e espanhóis. A eles se devia o monopólio da exploração de minérios americanos assim como a exclusividade da distribuição europeia de algumas especiarias e drogas das Índias. ${ }^{2}$

A viagem durou cerca de um ano e levou os dois homens às cidades ibéricas que então se destacavam pelo seu florescimento económico e pela sua riqueza cultural. Deixando Madrid naquele final de ano de 1564, a dupla passou por Badajoz em direcção a Lisboa. ${ }^{3} \mathrm{~A}$ chegada à fronteira portuguesa teve lugar

${ }^{1}$ Clusius/Charles de l'Écluse foi um dos mais importantes botânicos europeus do século xvI. Natural de Arras, destacou-se pela relevância da obra botânica que publicou. Particularmente atento à natureza das Índias e do Levante, ao longo de toda a sua vida, criou e centralizou uma importante rede epistolar através da qual recolheu notícias e especímenes e divulgou informações relativas ao mundo natural exótico então conhecido. Os diversos tratados publicados ao longo da sua vida foram compilados em duas grandes obras: Rariorum plantarum historia, Leiden, Jan Moretus, I60 I e Exoticorum libri decem, Leiden, Raphelengius, 1605 . Sobre a vida e obra deste importante botânico há recentes estudos editados por Egmond (2010) e Egmond et al (2007).

${ }^{2}$ Sobre o investimento de capitais dos Függer nas viagens de exploração ibéricas ver: Mathew (1997) ou Kellenbenz (2000).

${ }^{3}$ Em Boxer (1963: 25) pode ler-se: «Clusius accompanied Jacob Fugger on a botanizing espedition through the Iberian Peninsula between May 1564 and May 1565 . After visiting Salamanca, Madrid, Alcalá and other places, they left Spain for Portugal via Badajoz in September 1564, and must have reached Lisbon by the end of the month. Clusius stayed in Portugal until the middle of January 1565 , most of the time in Lisbon, its environs, though he went as far north as Coimbra. Leaving Portugal by way of Évora and Serpa, he reached Seville on the 18 January 1565 . He stayed in Seville for only a few days and then left on a rapid tour through southern Spain; nor did he return to this city before he started on his home ward journey via Madrid and Paris to Antwerp, which he reached in early June 1565.» Os dados relativos à viagem de Clusius estão dispersos na Rariorum aliquot stirpium per Hispanias observatarum Historia que posteriormente publicou em Antuérpia, em 1576. Esta edição veio mais tarde a constituir o primeiro volume da colectânea de textos que editou em i6or e que designou Rariorum Plantarum Historiae. Os dados que aqui se apresentam, 
entre finais de Outubro e princípios de Novembro. O itinerário escolhido pelo botânico retomou, em muitos momentos, o percurso efectuado por Hieronimus Münzer (I447-1508) durante a sua viagem à Península. ${ }^{4}$

Apesar de Münzer ter entrado por Badajoz e saído por Valença do Minho, rumo a Santiago de Compostela, Clusius seguiu as suas pisadas através das cidades alentejanas de Serpa e Évora até Lisboa e daí até Coimbra. ${ }^{5}$ A viagem de Münzer pelos campos lusitanos foi, no entanto, mais acelerada do que a de Clusius já que, para além de visitar mercados e palácios, o viajante alemão pretendia descrever a grandiosidade das cidades lusitanas que comparou, de forma sistemática, com as mais importantes vilas e cidades do Norte da Europa. ${ }^{6}$ A Clusius, interessava também proceder ao levantamento florístico da Península, o que o levou a hortos e pomares de mosteiros e conventos assim como a jardins particulares reconhecidos pelo exotismo dos exemplares botânicos neles cultivados.

Na sua passagem por Portugal e Espanha, naqueles anos de I564-1565, Clusius recolheu, analisou, comparou e identificou alguns dos endemismos da flora portuguesa. Os exemplares descritos foram posteriormente divulgados à comunidade erudita através do Rariorum aliquot stirpium per Hispanias observatarum historia (Antuérpia, I576). ${ }^{7}$ Para além dos exemplares vegetais

que descrevem o percurso geográfico de Clusius, foram criteriosamente identificados no trabalho de Ventura (I933: 7-40).

${ }^{4}$ Natural de Feldkirch (actualmente Vorarlberg, na Áustria), este médico formado em Pavia foi um dos mais destacados intelectuais do seu tempo. Autor de uma vasta obra científica, em áreas tão específicas como a cosmografia ou a astronomia, manteve contactos estreitos com as elites eruditas de então. De entre os périplos europeus que efectuou, destacamos a viagem à Península Ibérica que realizou em I494-I495 com alguns amigos naturais de Augsburgo e Nuremberga. Desta viagem elaborou um detalhado relato ao qual fazemos referência no presente trabalho (Münzer 2006).

${ }^{5}$ Hieronimus Münzer entrou em Portugal pela região de Badajoz-Elvas e seguiu por Évora, Montemor-o-Novo, Lisboa, Alverca, Santarém, Tomar, Coimbra, Porto, Barcelos, Ponte de Lima e Valença do Minho.

6 «Évora est plus grand qu'Ulm» (Münzer 2006: I26); «Cette ville [Lisbonne] est plus grande que Nuremberg» (Münzer 2006: 128).

${ }^{7}$ Publicado em 1576, o tratado foi recentemente traduzido para castelhano. No presente ensaio usaremos esta moderna versão como referência (Clusius, 2005). Como escreveu o botânico: «En aquel viaje [por Espanha] anoté para acordarme, la forma de la mayor parte de ellas, su lugar de nacimientos y sus nombres. Yo mismo dibujé también con carbón o con rúbrica la figura de algunas y, al volver de España, casi todas las traje secas o bien envié a los amigos desde allí sus semillas e incluso las propias plantas, naturalmente 
que analisou na Península Ibérica, Clusius, que dedicou a obra a Maximiliano II, incluiu, no final, um pequeno apêndice onde descreveu «Algunas plantas exóticas y hermosas traídas de la Tracia». ${ }^{8}$ Neste destacamos a sua descrição de exotismos orientais, nomeadamente, as tulipas, os jacintos, as anémonas, ou os ranúnculos (Clusius 2005: 347-359).

Esta viagem à Península Ibérica fazia parte da formação do jovem banqueiro. Na epístola dedicatória que inseriu no epítome latino de Colóquios dos Simples de Garcia de Orta, Aromatum et Simplicium (Antuérpia, 1567), que Clusius dirigiu ao «Magnifico Varão e Senhor Jacobo A. F. Fugger, companheiro em Kirchperg e Weissenhorn», ${ }^{9}$ escreveu:

Por sua vontade [António Fugger, pai de Jacob Fugger] terias percorrido não só a Alemanha e a Boémia, mas também as Gálias, a Itália e as Espanhas, quer dizer, quase toda a Europa. Uma vez percorridas estas, terias assim observado os usos, ritos e costumes de todos os povos que visitasses e com mais exactidão terias aprendido a sua língua. Disto posso dar testemunho eu, que, teu companheiro de estudos, contigo vivi durante dois anos e percorri a maior parte das Espanhas (Clusius 1964: 3-4).

las que pudieron soportar la lentitud del transporte, como las bulbosas y las tuberosas» (Clusius 2005: 67).

${ }^{8} \mathrm{Na}$ altura em que publicou esta obra, Clusius era o director dos jardins imperiais de Viena, cargo que desempenhou durante mais de uma década. Dedicado «Al muy invicto y poderoso Maximiliano II, emperador de los romanos», a obra continha, segundo Clusius, as descrições de «muchísimas plantas muy raras que son desconocidas en otros lugares.» Segundo assegurou o botánico ao mecenas, «Lo que sí puedo prometer es que tanto en su descripción como en sus dibujos del natural me he esforzado en no faltar a la verdad y en reproducir sólo las observaciones propias.»

${ }^{9}$ Jacob Függer (1542-1598) era o filho mais novo de Anton Függer (I493-1560) e Anna Rehlinger (15II-1548). À data da viagem que efectuou com Clusius, I564-1565, seu pai já tinha morrido. A viagem seria talvez um pretexto para inteirar o futuro herdeiro da amplitude dos negócios familiares. Os humanistas do século xvı viajavam com frequência. A viagem era, por muitos, considerada imprescindível para consolidar a formação humana e intelectual dos jovens de posses. Raramente viajavam sozinhos. Regra geral faziam-se acompanhar de tutores ou mestres que os apresentavam às elites eruditas, aos homens curiosos, aos aristocratas e agentes comerciais das cidades que visitavam. Clusius foi tutor de Jacob Függer e de Thomas Rehdiger. A ambos dedicou posteriormente obras botânicas. Sobre a relevância da viagem complemento da formação e educação dos jovens aristocratas ver, por exemplo: Findlen (1994: 155-193). 
Detentores de um importante filão no tráfico de produtos, drogas e especiarias das Índias, os Függer tinham feitores destacados na Península Ibérica, nomeadamente em Lisboa e Sevilha, com quem mantinham permanente contacto através de uma consistente troca epistolar.

Acompanhando o seu jovem pupilo, Clusius era o interlocutor adequado para estabelecer os contactos com estes agentes comerciais. Homem bem apadrinhado, é fácil de supor que tenha apresentado o seu companheiro de viagem tanto a eruditos como a nobres ou simples curiosos, que então constituíam as elites mercantis e culturais ibéricas. ${ }^{10}$

Em Lisboa, os dois viajantes inquiriram certamente os marinheiros sobre as suas aventuras ultramarinas, auscultaram os comerciantes sobre os preços e qualidades das suas mercadorias, deambularam maravilhados pelos armazéns da Casa de Índia, deixando-se encantar pela variedade das cores, pela estranheza dos animais, pela intensidade dos aromas e pelas preciosidades sem igual que por lá encontraram. ${ }^{11}$

Como descreveu Damião de Góis:

Seria preferível chamar-lhe [à Casa da Índia] empório opulentíssimo dos aromas, pérolas, rubis, esmeraldas e outros tipos de pedras preciosas que ano após ano nos são trazidas da Índia; com maior verdade se lhe poderia chamar armazém vastíssimo da prata e de ouro, já trabalhado e por trabalhar, [...] a abarrotar com tão gran-

${ }^{10}$ Ao longo desta obra, Clusius manteve-se bastante discreto relativamente aos portugueses com quem contactou. Aludiu apenas aos nomes de dois portugueses: D. Fernando Coutinho e Damião de Góis. Do primeiro, para além de lhe reconhecermos um belo jardim rodeado de murta, pouco mais podemos dizer. Em relação ao segundo, por ser um elemento tão relevante da nossa história cultural, abstemo-nos de caracterizar por considerar que, no contexto desta publicação, nunca o conseguiremos fazer de forma adequada. Remetemos o leitor interessado sobre esta personalidade para trabalhos de reconhecido fôlego como o de Hirch (1987) ou de Barreto (2002). Sobre os correspondentes castelhanos de Clusius ver Barona \& Gómez Font (1998) assim como Barona (2007: 99-118). Florike Egmond identificou mais de 300 correspondentes que Clusius contactou entre 1560 e i609. De entre as personalidades assinaladas encontram-se botânicos, médicos, coleccionadores, príncipes, cortesãos e aristocratas, mas também jardineiros, mareantes, aventureiros ou pilotos. Dos raros portugueses que esta investigadora identificou, um deles dá pelo nome de «Príncipe Manuel». Este personagem, muito provavelmente, seria Manuel de Portugal (1568-1638) filho de António de Portugal, Prior do Crato (1531-1595). Agradecemos à Professora Florike Egmond esta preciosa informação.

${ }^{11}$ A Casa da Mina e Tratos da Guiné instalou-se em Lisboa em 1482 e deu origem, em I50I, à Casa da Índia. 
de abundância de todos aqueles produtos, que, palavra de honra, a realidade excedia as expectativas, até porque víamos o que saltava aos olhos de todos e naquele momento quase se podia apertar nas mãos (Góis I980: I7I).

Quando os nossos dois visitantes chegaram à capital do império lusitano, vivia-se um intenso fervilhar no porto que se preparava para receber mais uma frota oriunda do Oriente. Das naus então aportadas ao cais descarregavam-se esplêndidas riquezas, aromas inebriantes, drogas valiosas e copiosas novidades das longínquas Índias. Para além dos fardos, arcas, vasos, sacas e barris contendo tecidos, especiarias, drogas, sementes, porcelanas, pedras preciosas e outras maravilhas, ecoavam no ancoradouro numerosos relatos que testemunhavam os prodígios avistados por todos quantos tinham andado noutros mun$\operatorname{dos}^{12}$

Damião de Góis desenhou a azáfama das gentes e a fartura que se vivia nos mercados de Lisboa:

Aqui [nas imediações do actual Terreiro do Trigo] está montado o mercado do peixe juntamente com o mercado de confeitaria, a que acorrem, todos os dias, peixeiros, salsicheiros, confeiteiros, talhantes, padeiros, doceiros, que se juntam em grupos para venderem tudo o que são géneros alimentícios e que eles trazem à cidade. Além disso, saltam à vista casa de mercadores, de bufarinheiros, de taberneiros, de estalajadeiros, de tecelões, todas bem providas (Góis 1980: 167).

Observador rigoroso e atento, Clusius não deixou escapar o ínfimo detalhe sobre produtos alimentares, as drogas e os simples que aí se descarregavam assim como das histórias vividas e contadas por aqueles que, vindos do Oriente, desembarcavam em terra firme.

${ }^{12}$ A constante chegada e partida de frotas mantinha o porto de Lisboa em permanente agitação. Mercadores, estivadores, marinheiros, soldados, missionários, pilotos, curiosos e espiões rondavam os cais enchendo os ares da capital de um irresistível burburinho de aventuras, lendas, mitos e feitos. Sobre as viagens na Carreira da Índia ver Domingues (1990: 50-75). Sobre os mercados e produtos à venda na Lisboa de Quinhentos ver Couto (2006: I17-124). 


\section{UM ENCONTRO MUITO PECULIAR}

Recém-chegados das Índias Orientais foram desembarcados em Lisboa barris contendo uma valiosa mercadoria: os numerosos cadernos de uma obra publicada em Goa inteiramente dedicada aos recursos naturais do Oriente. Referimo-nos a Colóquios dos Simples e Drogas he Cousas Mediçinais da Índia, da autoria de Garcia de Orta (ca. I500-1568), um dos mais sábios médicos portugueses destacados na Ásia.

Formado nas universidades castelhanas de Salamanca e Alcalá de Henares, docente por um curto período nas Escolas Gerais de Lisboa, Garcia de Orta partiu para a Índia em I534 como médico pessoal de Martim Afonso de Sousa (1500-1572), o então Capitão-Mor da Armada. ${ }^{13}$

O físico nunca mais regressou à Europa. Ciente da sua discreta passagem pelas crónicas portuguesas coevas, Orta preocupou-se em revelar aos seus leitores passos da sua vida por terras asiáticas e facetas da sua personalidade. Assim, em múltiplos momentos, a obra assumiu um registo autobiográfico. Aos olhos dos seus leitores, Orta surgiu como um homem de gosto sofisticado, um médico experimentado, um profissional competente, um conversador subtil, um hábil gestor de palavras e imagens. O médico descreveu-se, enfim, como um abastado físico residente na capital do Estado português da Índia. A referência textual a um vasto conjunto de obras científicas transmitiu confiança às suas argumentações. ${ }^{14}$ A descrição desta personalidade versátil e culta revelou-se da maior importância já que constituiu a base para a credibilidade de Garcia de Orta como uma testemunha «digna de fé». Uma das novidades deste tratado devotado à matéria médica do Oriente, resultou da valorização de relatos de numerosas testemunhas que só a autoridade do físico podia aceitar ou recusar. Deste modo, a confiança do leitor no juízo do médico revelou-se um requisito fundamental para o sucesso deste projecto editorial. ${ }^{15}$

${ }^{13}$ Fidalgo arrojado, autor de feitos tão valorosos como polémicos, Martim Afonso de Sousa viajou para Oriente onde desempenhou diferentes funções governativas: Capitão-Mor da Armada (I534-I538) e Governador (I542-I545). Sobre este aristocrata ver Albuquerque (1989) e Pelúcia (2007).

${ }^{14}$ Orta transmitiu a imagem de um sábio no seu gabinete de trabalho, detentor de uma ampla biblioteca onde guardava os mais consagrados tratados médico-botânicos. Sobre a livraria de Orta ver Loureiro (2008: I35-I45).

${ }^{15}$ A experiência clínica de Orta no Oriente, a observação das práticas de hakims e físicos 
Redigida em português, descrevendo as conversas entre dois médicos ibéricos, Colóquios dos Simples apresentou os mais actualizados saberes sobre os principais recursos orientais. Para cada produto, Garcia de Orta apresentou notícias detalhadas sobre a origem, utilidade, preços, mercados, rotas de distribuição e aplicações terapêuticas. ${ }^{16}$ Útil nos hospitais do Oriente como nas boticas das fortalezas, valiosa nos portos como nos mercados locais, a obra revestiu-se de grande relevância prática e científica, em Portugal e na Europa, mas também de uma enorme importância estratégica e comercial. ${ }^{17}$

Ao embater em Colóquios dos Simples, Clusius encontrou aquela raridade que viria a determinar, de forma inequívoca, o seu futuro percurso profissional. ${ }^{18}$

Escreveu Clusius: «Nesta viagem por Espanha encontrei por acaso um livro que, nascido em Goa, fora trazido recentemente da Índia Oriental» (Clusius 1964: 4). No exemplar goês que pertenceu a Clusius, e que se encontra guardado na Biblioteca da Universidade de Cambridge, pode ler-se uma nota redigida por Clusius. ${ }^{19}$ Nas exéquias de Clusius, o médico holandês Aelius

gentios assim como o juízo sobre o valor do testemunho dos seus informadores constituíram ferramentas fundamentais na construção da argumentação do médico. A sua autoridade radicou, em grande medida, na figura digna de confiança que Garcia de Orta desenhou para si.

${ }^{16}$ Para além da obra de Ficalho (I886), onde se podem encontrar preciosas apreciações sobre a obra deste médico, parece-nos útil realçar neste ponto alguns dos estudos sobre Garcia de Orta e Colóquios dos Simples que têm sido recentemente publicados em Portugal de entre os quais destacamos Mendes \& Fragoso (2008) assim como Mendes (2009) e Carvalho (2012).

${ }^{17}$ Sobre a relevância de Colóquios dos Simples no Império português ver Carvalho (2012: 210-220).

${ }^{18}$ A partir de 1567 , data da primeira edição do epítome latino do tratado de Orta, Clusius privilegiou a edição de obras relacionadas com o mundo natural dos espaços extra-europeus. Assim, após a edição da versão latina da obra de Orta, o botânico publicou o epítome latino das obras de Nicolas Monardes, Historia Medicinal de las cosas que se traen de las nuestras Indias Occidentales, Sevilha, 1574. [De simplicibus medicamentis ex Occidentali India delatis, quorum in medicina usus est, Antuérpia, 1574] e de Cristóvão da Costa, Tractado de las Drogas y medicinas de las Indias Orientales, Burgos, 1578 [Aromatum et medicamentorum in Orientali India nascentium liber, Antuérpia, 1582]. A estes tratados juntou mais tarde o de Pierre Belon du Mans, Plurimarum singularum \& memorabilium rerum in Graecia, Asia, Aegypto, Indaeo Arabia, allisque exteris provinciis... Leiden, I605. tendo editado uma versão latina conjunta de todas estas obras em Exoticorum libri decem, Leiden, I605.

${ }^{19}$ Como escreveu Boxer: «It was during this trip that Clusius secured a copy of the Colóquios de Garcia d'Orta, and fortunately we know the exact date and place that he did so. This very copy, containing numerous marginal notes in Clusius' neat handwriting and with an inscription in his autograph on the flyleaf reading is preserved in the library of the Cambridge University» (Boxer, 1963: 25-27). 


\title{
A R O M A T V M,
}

\section{E T}

\section{SIMPIICIVM ALIQVOT}

\section{LE I I A M E TOR VMAIVD}

\section{INDOS NASCENTIVN}

\author{
H ISTORIA: - $\cdots$
}

Ante biennium quidem Lufitanica lingua per Dialogos confcripta, D. G A R C I A A I ho R T O, Proregis Indię Medico,auctore:

Nunc vero primùm Latina facia, \&o in Epitomen contracta à C A R O LO C L.VS IO Atrebate:

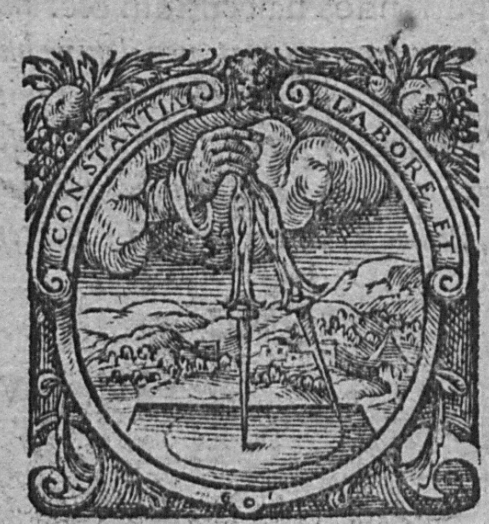

ANT YER PIAS

Ex officina Chriftophori Plantini

cIJ. IO. IXVII.

CVM DRXVIIEGIO.

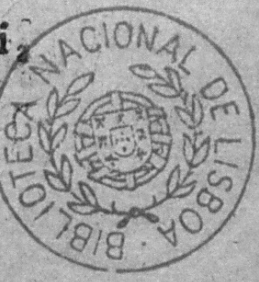

Frontispício de Aromatum et Simplicium, Antuérpia, 1567. 
Everardus Vorstius (1565-1624) dirigiu ao seu amigo uma comovida oração fúnebre. Nela, este professor da Universidade de Leiden confirmou que Clusius encontrara os «Discursos de garçiae ab Orta» $[$ sic $]$ em Lisboa. ${ }^{20}$

Preocupava-o, no entanto, o facto de estar redigida em português, idioma estranho a muitos. Como escreveu:

Afligia-me bastante o facto de que estivesse escrito numa língua que por poucos era compreendida. Parece que o autor, homem muito erudito, o quis escrever em lusitano, e teve as suas razões, porquanto em latim era mais difícil de escrever. [...] Como vi que ninguém o tentasse [verter para latim], não consegui adiar este desejo por mais tempo e preferi tomar este encargo, apesar de superior às minhas forças, do que permitir que os Lusitanos fossem os únicos a gozar da utilidade deste livro (Clusius 1964: 5).

Clusius dedicou-se, de imediato, à reformulação do texto de Orta. Mantendo intactos os conteúdos científicos, o botânico deu à estampa uma nova obra, Aromatum et Simplicium, na qual expôs, de forma mais adequada ao público do Norte da Europa, as novidades acabadas de chegar das Índias Orientais. O pequeno formato do volume in-octavo, para além de incluir algumas anotações e comentários do botânico, apresentava sugestivas figuras de algumas drogas e especiarias. O autor dos desenhos, Peter van der Borcht (I545I608), era um dos mais destacados artistas ao serviço da oficina Plantin. O investimento substancial na publicação de uma obra ilustrada, integralmente dedicada ao mundo natural, revela bem o interesse manifestado pelos leitores por obras desta natureza. Saída dos prelos das oficinas de Christoph Plantin em I567, os I.250 exemplares esgotaram de imediato. Nos anos seguintes, Clusius continuou a reformular e acrescentar detalhes na edição original, publicando sucessivas versões e anotações. A intensa procura desta obra é atestada pela imensa circulação da informação nela contida que pode ser confirmada pelas múltiplas referências a este tratado assim como pelas traduções que dele foram feitas. ${ }^{21}$

${ }^{20}$ Esta oração fúnebre foi publicada dois anos mais tarde (Vorstius, i6ıi ).

${ }^{21}$ A circulação do saber validado por Orta verificou-se não apenas devido ao epítome latino de Clusius mas também às correspondentes traduções italianas e francesas. Também a inclusão de extensas anotações retiradas do Aromatum et Simplicium em obras de grande fôlego, como as de Jacques Dálechamps, Historia Naturalis Plantarum, Lião, I586I 587 ou a Caspard Bahuin, Pinax, Basileia, I623, entre outras, assegurou a ampla difusão 


\section{PORTUGAL PAíS DE EXTRAVAGÂNCIAS}

A convivência com o mundo exótico que inundava toda a Lisboa materializava-se, não apenas por estes encontros entre Oriente e Ocidente ou pela abundância de produtos raros em circulação nos mercados mas também na variedade de árvores exóticas e plantas extravagantes que cresciam nos seus jardins. Espantado com o dragoeiro que encontrou num convento lisboeta, Clusius apressou-se a descrevê-lo em detalhe.

La descripción de este árbol la han acometido pocos y de forma muy incompleta. Por esto quiero describirlo aquí y empezar con él nuestro estudio, ya que es muy raro, sobre todo en nuestra Europa, y, si no me equivoco, desconocido por los botánicos (Clusius 2005: 69).

Como escreveu:

La primera vez que vi este árbol fue en Lisboa, en el año 1564 de la salvación humana, en la parte posterior de un Mosterio dedicado a la Santísima Virgen que llaman da Gracia (Clusius 2005: 70). ${ }^{22}$

Plantado no jardim conventual, tal como Hieronimus Münzer havia prometido, o botânico não deixou de se maravilhar com a excentricidade desta monocotiledónea que a tradição descrevia como estando ligada a um dragão. ${ }^{23} \mathrm{Na}$ verdade, os bestiários medievais associavam a origem da valiosa re-

do saber autorizado por Garcia de Orta na Europa culta de então. De igual modo, não deve ser descurada a relevância de outras obras como a de Juan Fragoso, Discurso de las cosas aromáticas, Madrid, I572, e de Cristóvão da Costa, Tractado de las Drogas, Burgos, I578, que produziram compêndios redigidos em castelhano amplamente baseados na obra de Orta. Sobre a edição e circulação da obra de Clusius ver Nave \& Imhof (1993), para além dos recentes trabalhos editados por Florike Egmond e colaboradores acima referidos. Relativamente à apropriação do texto de Garcia de Orta pelos médicos ibéricos, ver Carvalho (20II).

${ }^{22}$ Damião de Góis referiu-se a este Mosteiro, fundado intramuros, em I27I. O convento era a cabeça da Ordem e podia albergar centenas de pessoas, tendo tido importantes obras de beneficiação durante o século xvı.

${ }^{23}$ «Il y avait aussi [monastère des frères mineures] un arbre qu'on appelle dragon, d'òu coulle le sang de dragon, uns sève rouge. Il y a aussi trois dragonniers dans le Monastère de Saint-Augustin, tout en haut du château» (Münzer, 2006: I29). As descrições dos exotismos 
sina que se extraía desta árvore às lágrimas de um dragão que jazia no subsolo. Recolhida à mão, a excrescência que escorria ao longo do tronco era usada, desde tempos remotos, como corante para além de se lhe reconhecerem propriedades medicinais, nomeadamente hemostáticas. ${ }^{24}$

O seu enorme interesse por esta raridade levou-o a incluí-la na sua própria colecção de maravilhas. Como escreveu:

[...] al año siguiente un amigo me regaló una rama, o racimo, arrancada de este mismo árbol [dragoeiro]. Esta rama (que aun hoy conservo en mi casa con algunas hojas, un trozo de corteza y una lágrima que yo mismo arranqué con mis manos) tiene un pie o más de largo y a ella se adhieren otras ramas pequeñas cargadas de abundante y compacto fruto arracimado (Clusius 2005: 70).

Ao olhar atento do botânico também não escapou uma espécie de pimentos que crescia nos jardins de outro mosteiro nos arredores de Lisboa ou ao aloés que brotava junto às muralhas do Castelo de São Jorge. O encontro com a harmoniosa vegetação destas plantas exóticas nos parques da capital é revelador da radicalidade do diálogo transcontinental que provocava quem passava por Lisboa.

A afluência de gentes chegadas das mais remotas paragens, a diversidade de linguajares e dialectos que ecoava pelas ruas, a variedade de produtos de origens longínquas à venda nos mercados, testemunhava que a riqueza da cidade não se esgotava no valor das mercadorias que nela se trocava mas também da pluralidade que nela se vivia.

que Münzer avistou em Portugal são extraordinárias pelo detalhe. Os exotismos que Portugal exibia foram registados na sua obra: o camelo no palácio real de Évora; a pele de serpente, proveniente de África colocada sobre a porta da igreja de São Blásio; o crocodilo pendurado no tecto do mosteiro dos frades menores; os leões no jardim do Castelo de S. Jorge; o pelicano e os bambus gigantes do Mosteiro de Santa Maria da Luz, entre tantos outros que o relator descreveu.

${ }^{24}$ Planta rara na Europa continental, a espécie Dracaena draco L. desenvolvia-se naturalmente nos arquipélagos atlânticos: Açores, Madeira, Canárias e Cabo Verde. Descrito nos tratados de matéria médica da antiguidade, destas plantas de porte bizarro extraía-se o sangue-de-dragão. Apesar de o mais procurado ser o proveniente de uma outra espécie do mesmo Género, a Dracaena cinnabari, proveniente da ilha de Socotorá (actual Iémen), a descoberta de uma fonte alternativa deste poderoso corante nas ilhas da Macaronésia e a sua aclimatação nos jardins portugueses maravilhou os viajantes europeus que atravessavam toda a Europa para os vir admirar. 


\section{POR MONTES E VALES}

Discípulo atento de Guillaume Rondelet (1507-1566), um dos seus mais destacados mestres de Montpellier, Clusius, durante a sua passagem pela Lusitânia, não prescindiu das explorações botânicas. ${ }^{25}$

Abandonando as estradas, tal como aprendera com Rondelet, privilegiou a viagem pelos campos, seguiu os trilhos dos rebanhos, recolheu raízes, rizomas e tubérculos, observou árvores e ervas, inquiriu as populações sobre os usos locais das plantas e frutos. Esta abordagem sistemática da natureza lusitana permitiu ao botânico identificar na flora de Portugal uma riqueza, até então, insuspeitada.

Assim, nas suas deambulações pelos campos recolheu amostras de espécies vegetais que desconhecia e registou as suas características. Destaca-se uma variedade de Iris, que encontrou em Coimbra e que Clusius designou biflora ${ }^{26}$ por florir duas vezes, assim como um linho bravo ${ }^{27}$ que encontrou junto de uma ermida nos arredores de Coimbra, ou a selaginela que apelidou de «hierba delicadísima» que nunca vira e a que chamara «musgo terrestre lusitano». ${ }^{28}$

No seu périplo por Portugal, Clusius visitou Cascais, Pena e Sintra assim como Rio Frio, Aldeia Galega e Penha Longa. As descrições da flora lusitana

${ }^{25}$ Rondelet foi um dos mais destacados professores de medicina na Universidade de Montpellier. Autor de uma vasta obra sobre peixes, Rondelet destacou-se entre os eruditos de então pelo seu entusiasmo pelas expedições botânicas. O médico incentivou os seus discípulos a constituírem os seus próprios herbários de plantas secas que lhes permitiam analisar com mais detalhe os especímenes avistados. De entre os notáveis com quem Rondelet se cruzou destacam-se os nomes de Pierre Belon du Mans, Conrad Gessner, Clusius ou Ulysses Aldrovandi. Sobre a vida de Clusius em Montpellier ver, por exemplo Egmond (2007: 65-98).

${ }^{26}$ «En Portugal [el lirio portugués o bifloro] crece por todas las partes al norte del Tajo, unas veces sobre suelo fértil, otras en terrenos completamente pedregosos. Florecida la recogí por primera vez en noviembre cerca de Coimbra, la celebérrima universidad portuguesa, y desde allí la envié y la traje a nuestra tierra» (Clusius 2005: 225).

${ }^{27}$ «Sólo recuerdo haber visto esta planta [el lino silvestre de hoja ancha] junto a la ciudad portuguesa de Colibria, vulgarmente conocida como Coimbra, ciudad famosa por su célebre universidad. La encontré junto a un templo abandonado y estaba rebrotando en el mes de noviembre» (Clusius 2005: 263).

${ }^{28}$ «Este género de musgo sólo lo he visto en las terrazas umbrías de los olivares próximos de la ciudad portuguesa de Colibria [sic] y a la más célebre universidad de todo el reino, llamada vulgarmente Coimbra, al otro lado del río Mondego» (Clusius 2005ः 340). 
que apresentou na sua obra testemunham que percorreu as estradas rumo a Coimbra, passando por Montemor-o-Novo e Tomar. A cidade do Mondego terá sido o extremo mais a Norte de Portugal que visitou. É provável que aí se tenha avistado com alguns colegas de ofício com o objectivo de esclarecer questões botânicas ou de enriquecer a sua rede de contactos. Apesar de não termos quaisquer dados que nos permitam comprovar o encontro de Clusius com a comunidade de sábios destacados na Universidade de Coimbra, parece-nos plausível que estas conversas tenham ocorrido. De entre os mais destacados membros do corpo docente da escola conimbricense realçamos o nome de Tomás Rodrigues da Veiga (I5I3-1579), ilustre galenista e comentador de textos médicos. ${ }^{29}$

\section{NOTAS FINAIS}

Clusius deixou Portugal em finais de Janeiro de 1565, passando por Évora e Serpa em direcção a Sevilha. Na bagagem levava as peculiaridades da flora de Portugal, o calor das suas gentes, a amenidade dos seus Invernos, algumas curiosidades encontradas em Lisboa, mas, acima de tudo, levava uma enorme preciosidade: um exemplar dos Colóquios dos Simples recém-publicado nas Índias Orientais onde se caracterizava, de forma inovadora, a botânica e a matéria médica asiática.

Para além desta pequena maravilha que marcou de forma indelével o seu percurso profissional, Clusius levou consigo a memória de um país que o agradou. Como referiu Maria Augusta Gersão Ventura, o botânico enriqueceu a nossa toponímia com gostosos adjectivos: Tomar, «aldeia insigne»; Coimbra, «notável pela sua célebre Universidade», e nomeou respeitosamente Damião de Góis, D. Fernando Coutinho ou, mais tarde, Garcia de Orta. Para esta au-

${ }^{29}$ São escassas as notícias sobre este médico. Natural de Évora, este comentador de Galeno destacou-se pela sua vasta erudição mas também pela sua ampla prática de campo. Conhecedor do património florístico português, Rodrigues da Veiga ocupava as suas horas de lazer caminhando pelos campos e recolhendo amostras de plantas que prensava e secava. Sobre este sábio ver Rocha de Brito (1949: 402-409). Em Colóquios dos Simples, Garcia de Orta aludiu a este médico no Colóquio da Canela (Orta I987: I, 216). Neste tratado encontra-se também, entre os paratextos, uma carta que o médico de D. Constantino de Bragança (Vice-Rei da Índia I558-I56r), o Dr. Dimas Bosque, dirigiu a este académico de Coimbra (Orta I: I2-I3). 
tora, o respeito do botânico por Portugal ficou expresso, de forma inequívoca, no Exoticorum que publicou em i605. Nesta obra, ao descrever uma ave exótica que os holandeses tinham trazido da ilha Maurícia, Clusius recordou que esta ilha já havia sido antes descrita pelos portugueses que então lhe haviam chamado «Ilha do Cirne» (Ventura 1942: 5-8). Recordar a designação primitiva foi, na opinião desta estudiosa, uma homenagem que o botânico prestou aos portugueses e a Portugal, que esquecido da passada grandeza, jazia então sob o jugo castelhano.

Ponto de confluência de práticas, saberes e tradições, país de uma notável riqueza natural e humana, a passagem por Portugal proporcionou a Clusius o encontro com uma realidade múltipla que marcou, de forma decisiva, a sua vida e trouxe à Europa um conhecimento mais cabal do mundo natural dos territórios portugueses.

\section{AGRADECIMENTOS}

Gostava de expressar o meu reconhecimento a Isabel Soler pelo paciente e amável convite que me dirigiu para participar nesta publicação assim como a Rui Manuel Loureiro pela revisão final do texto.

\section{REFERÊNCIAS BIBLIOGRÁFICAS}

Albuquerque, Luís de (1989). Martim Afonso de Sousa. Lisboa: Publicações Alfa.

Barona, Josep Lluís (2007). «Clusius' Exchange of botanical information with Spanish scholars». Florike Egmond et al. Carolus Clusius. Towards a cultural history of Renaissance naturalist. Amesterdão: Edita KNAW, 99-118.

Barona, Josep Lluís; Gómez Font, Xavier (1998). La correspondencia de Carolus Clusus con los científicos españoles. Valência: Seminari d'Estudis sobre la Ciència.

Barreto, Luis Filipe (2002). Damião de Goes. Os caminhos de um Humanista. Lisboa: CTT.

Boxer, Charles R. (1963). Two pioneers in tropical medicine: Garcia d'Orta and Nicolas Monardes. Londres: The Hispanic and Luso-Brasilian Councils.

Brito, Rocha de (1949). «O Doutor Rodrigues da Veiga ilustre ervanário». Jornal do Médico, Lisboa, I3 (323), 402-409.

Carvalho, Teresa Nobre de (2008). «Colóquios dos Simples de Garcia de Orta: Conversas no interior da Índia». Anabela Mendes, Gabriela Fragoso (ed.). Actas do 
Colóquio Internacional e Interdisciplinar Garcia de Orta e Alexander von Humbol$d t$. Lisboa: Universidade Católica Portuguesa, 165-175.

Carvalho, Teresa Nobre de (201I). «A apropriação de Colóquios dos Simples por dois médicos ibéricos de Quinhentos». Palmira Fontes da Costa; Adelino Cardoso (ed.). Percursos na História do Livro Médico (I450-1800). Lisboa: Colibri, 59-72.

Carvalho, Teresa Nobre de (2012). O mundo natural asiático aos olhos do Ocidente.

Contribuição dos textos ibéricos quinhentistas para a construção de uma nova consciência europeia sobre a Ásia. Tese de Doutoramento. Lisboa: Universidade de Lisboa.

Clusius (I60I). Rariorum plantarum historia. Leiden: Jan Moretus.

Clusius (1605). Exoticorum libri decem. Leiden: Raphelengius.

Clusius (1964). Aromatum et simplicium aliquot medicamentorum apud Indos nascentium Historia. Introdução e versão portuguesa de Jaime Walter e Padre Manuel Alves. Lisboa: Junta de Investigações do Ultramar [1567].

Clusius (2005). Descripción de algunas plantas raras encontradas en España y Portugal. Edición de Luis Rámon-Laca Menéndez de Luarca y Ramón Morales Valverde. Junta de Castilla y León: Consejería de Cultura y Turismo [1576].

Couto, Dejanirah (2006). História de Lisboa. Lisboa: Gótica.

Domingues, Francisco Contente (1990). «Navios e marinheiros». Carlos Araújo (dir.). Lisboa e os Descobrimentos: I415-1580: a invenção do mundo pelos navegadores portugueses. Direcção da edição de Carlos Araújo. Lisboa: Terramar, 50-75.

Egmond, Florike (2010). The world of Carolus Clusius: Natural history in the making: I550-1610. Londres: Pickering \& Chatto.

Egmond, Florike; Hoftizzer, Paul; Visser, Robert (2007). Carolus Clusius: Towards a cultural history of a Renaissance naturalist. Amesterdão: Edita KNAW.

Ficalho, Conde de (I886). Garcia de Orta e o seu tempo. Lisboa: INCM.

Findlen, Paula (1994). Possessing Nature, Museums, collecting, and scientific culture in Early Modern Italy. Berkeley: University of California Press.

Góıs, Damião de (1980). Elogio da cidade de Lisboa. Lisboa: Guimarães Editores.

Hirch, Elisabeth Feist (1987). Damião de Goes. Lisboa: Fundação Calouste Gulbenkian. Kellenbenz, Hermann (2000). Los Fugger en España y Portugal hasta I560. Junta de Castilla y León: Salamanca.

LEWIS, Gillian (2007). «Clusius in Montpellier, I55I-1554: A humanist education completed?». Florike Egmond et al. Carolus Clusius: Towards a cultural history of a Renaissance naturalist. Amesterdão: Edita-KNAW, 65-98.

Loureiro, Rui Manuel (2008). «Garcia de Orta e os Colóquios dos Simples: Observações de um viajante sedentário». Anabela Mendes; Gabriela Fragoso (ed.). Actas do Colóquio Internacional e Interdisciplinar Garcia de Orta e Alexander von Humboldt. Lisboa: Universidade Católica Portuguesa, I35-145.

Mathew, K. S. (1997). Indo-portuguese trade and the Fuggers of Germany sixteenth century. New Dehli: Manohar. 
Mendes, Anabela (ed.) (2009). Proceedings of the International and transdisciplinary Congress Garcia de Orta and Alexander von Humboldt across the East and the West. Lisboa: Universidade Católica Portuguesa.

Mendes, Anabela; Fragoso, Gabriela (ed.) (2008). Actas do Colóquios Interdisciplinar Garcia de Orta e Alexander von Humboldt. Lisboa: Universidade Católica Portuguesa.

Münzer, Jerôme (2006). Voyage en Espagne et au Portugal (I494-I495). Paris: Les Belles Lettres.

Nave, Francine; Imhof, D. (ed.) (1993). Botany in the Low Countries (end of the $15^{\text {th }}$ century - ca. I650), Plantin-Moretus Museum Exhibition. Gent: Snoeck-Ducaju \& Zoon.

OrтA, Garcia (1563). Colóquios dos Simples, e Drogas he cousas mediçinais de Índia, Goa: Joannes de Endem.

Orta, Garcia (1987). Colóquios dos Simples e Drogas da Índia. Edição anotada e comentada pelo Conde de Ficalho. Lisboa: Imprensa Nacional Casa da Moeda [1591-1595], 2 volumes.

Pelúcia, Alexandra (2007). Martim Afonso de Sousa e a sua linhagem: a elite dirigente do Império Português nos reinados de D. João III e D. Sebastião. Dissertação de Doutoramento em História. Lisboa: UNL-FCSH.

Ventura, Augusta Faria de Gersão, (1933). «Clusio Portugal e os portugueses nas suas obras», separata de Petrus Nonius. Coimbra: Imprensa da Universidade, vol. I, 7-40.

Ventura, Maria Augusta Gersão (1942). «Duas pequenas notas à margem das obras de Clusio», separata Liceus de Portugal, I4: I-8.

VorTius, Everardus (I6II). Oratio funebris in obitum Caroli Clusii. Leiden: Raphelengius. 